\title{
Direct microscopic examination of imprints in patients undergoing cardiac valve replacement Frédéric Wallet ${ }^{* 1}$, Donatien Moukassa ${ }^{2}$, Micheline Roussel-Delvallez ${ }^{1}$, Agnes Wacrenier ${ }^{2}$ and René $\mathrm{J}^{\mathrm{Courcol}^{1}}$
}


Hôpital A. Calmette, CHRU Lille, France

E-mail: Frédéric Wallet* - fwallet@chru-lille.fr; Donatien Moukassa - dmoukassa@chru-lille.fr; Micheline RousselDelvallez - mroussel@chru-lille.fr; Agnes Wacrenier - awacrenier@chru-lille.fr; René J Courcol - ccourcol@chru-lille.fr

${ }^{*}$ Corresponding author

Published: 29 October 2001

BMC Clinical Pathology 200I, I:6

This article is available from: http://www.biomedcentral.com/1472-6890/1/6

(C) 200I Wallet et al; licensee BioMed Central Ltd. Verbatim copying and redistribution of this article are permitted in any medium for any non-commercial purpose, provided this notice is preserved along with the article's original URL. For commercial use, contact info@biomedcentral.com
Received: 6 June 2001
Accepted: 29 October 2001

\begin{abstract}
Background: Bacteriological analysis of cardiac valves might be indicated in patients with suspected endocarditis.

Methods: We report here a prospective study on fifty-three consecutive patients whose native valves were sent to the bacteriological and pathological laboratories, to investigate the performance of direct microscopic examination of imprints and valve culture.

Results: On the basis of a histopathological gold standard to classify the inflammatory valve process, the sensitivity, the specificity, the positive and the negative predictive values of direct microscopic examination of imprints and valve culture were $21 \%, 100 \%, 100 \%, 60 \%$, and $21 \%, 72 \%$, $38 \%, 52 \%$ respectively. This weak threshold of the direct microscopic examination of imprints could be due to antimicrobial therapy prescribed before cardiac surgery and the fact that the patients came from a tertiary hospital receiving patients with a prolonged history of endocarditis.
\end{abstract}

Conclusion: Clinical context and histopathology are indispensable when analyzing the imprints and valve culture.

\section{Background}

Infective endocarditis accounts for a small fraction of the total number of replaced valves. Histopathologic examination of these tissues removed during surgery is a standard practice in most hospitals. Direct microscopic examination of imprints of the valve is not usually requested. However, bacteriological analysis of cardiac valves might be advised in patients with suspected endocarditis [1]. Laboratories often perform analysis without clinical information. We report here a prospective study on 53 native valves sent to both bacteriological and pathological laboratories to investigate the performance of direct microscopic examination of imprints (DMEI) and valve culture to confirm and/or find the etiologic agent of acute endocarditis $[2,3]$. The aim of the study was to determine if routine direct microscopic examination of imprints and the culture of the native valves are informative for confirming and diagnosing endocarditis, using the histopathology as gold standard defining an evolutive inflammatory process. 


\section{Materials and methods Valve Study}

53 native valves were removed aseptically from patients submitted to cardiac surgery. They were sampled and carried out in sterile containers without medium. The heart valves were manipulated under a laminar flow unit. Portions of the valve showing disease (vegetations, thrombi) were separated into two parts: the first for bacteriological study and the second for pathological study. Before adding formalin, smears of the lesions were made on sterile slides before staining (Gram, May-GrünwaldGiemsa, Gimenez stains) for direct microscopic examination of imprints.

\section{Bacteriological processing}

The valve tissue was ground in $1 \mathrm{ml}$ of brain-heart broth with a mortar and pestle, and then cultured onto 5\% sheep blood, chocolate + isovitalex agar and in a paraffined brain-heart broth and Todd-Hewitt broth. The plates were incubated both in aerobic atmosphere and under carbon dioxide atmosphere (5\%) for 10 days at $37^{\circ} \mathrm{C}$. The broths were kept for 1 month (with subcultures at day 8 and day 30) [2,3]. A chocolate agar was incubated under carbon dioxide atmosphere (5\%) for 1 month for Bartonella sp detection. A piece of the valve was deep frozen at $-80^{\circ} \mathrm{C}$. Standard microbiological techniques were performed to identify the bacteria. Results of the May-Grünwald-Giemsa and Gram stains were reported as direct microscopic examination of imprints as follows: rare ( $\leq 1$ per oil immersion [X 1000] field), $1+(2-9$ per oil immersion [X 1000] field), $2+(10-50$ per oil immersion [X 1000] field), $3+(>50$ per oil immersion [X 1000] field).

\section{Pathological processing}

The tissue specimens were fixed in 10\% neutral formalin and embedded in paraffin. Consecutive $5 \mu \mathrm{m}$ sections were stained by hematoxylin-eosin-saffron-astra blue (HES), Gram, Gomori and Periodic Acid Shiff stain methods. The HES allowed us to classify the inflammatory response of the host as acute or chronic/sequellar inflammation [4] considered as the gold standard for evaluating the bacteriological results. The other stains gave information about the presence or absence of microorganisms: this step was considered a direct pathological examination (DPE).

\section{Patients}

53 patients admitted to the cardiology hospital were included in this study over two years (February 1997-February 1999). After the valve laboratory studies, clinical features and other biological parameters were retrospectively collected as follows: blood cultures performed before and during surgery, antimicrobial therapy prescribed, intracellular bacteria serologies (Bartonella,
Coxiella, Chlamydiae, Legionella) if the data were available. The number of positive blood cultures was not always available in the results obtained before surgery.

\section{Results and discussion}

During this prospective study over 2 years, 989 native cardiac valves were removed in the cardiology ward. Among these, 53 (5.3\%) were sent to both pathology and bacteriology laboratories because endocarditis was suspected during surgery or because the patient was known to have suffered an endocarditis in the previous months. These 53 valves came from 42 men and 11 women (mean age 50.4 years). The valves were classified as follows: 19 mitral valves, 31 aortic valves, 2 tricuspid valves and 1 pulmonary valve. The pathological classification revealed 24 evolutive acute infectious processes considered as true positive and 29 chronic/sequellar inflammatory processes considered as true negative. The detailed results for each patient are reported in Tables 1 (evolutive acute infections) and 2 (chronic/sequellar inflammatory process). Among the 24 with evolutive acute endocarditis, 23 patients were classified with a definite infective endocarditis according to Duke University [5]: two clinical major criteria +/- one pathologic criteria. Among the 29 other patients, 9 were classified with a definite infective endocarditis according to Duke University and 20 as possible infective On the basis of the histopathological gold standard, the sensitivity, the specificity, the positive predictive value (PPV) and the negative predictive value (NPV) of the DMEI and of the culture are reported on Table 3. The performance of the DPE is also reported in the Table 3 . The weak sensitivity of the DMEI could be explained by the thickness of the tissue in contact on the smears performed, and by the antimicrobial therapy decreasing the inoculum. The DPE performed in the tissue is more interesting, giving a sensitivity of $71 \%$ and a specificity of $90 \%$. Similar results were described by Chuard et al. [1] revealing the underfullness of direct examination because a negative result does not eliminate the diagnosis in treated patients. The status of the histopathological lesion seems to be more informative of the evolution of the illness. This could be due to the antimicrobial therapy prescribed before cardiac surgery. In our study, $78 \%$ of patients had received antibiotics at the time of cardiac surgery. Prescribed antibiotics were always beta-lactams with or without another antibiotic. If DMEI was positive (patients $2,4,5,8,9)$, that did not necessarily indicate antibiotic failure because the bacteria observed were dead.

The valve cultures were negative in 40 patients. In the 33 patients with retrospective documentation, $84 \%$ (28/ 33 ) received antibiotics and $60 \%(20 / 33)$ had positive blood cultures before cardiac surgery. In those with acute endocarditis, $71 \%(15 / 21)$ had positive blood cul- 
Table I: Evolutive acute infections: results of DMEI, DPE, culture of valve and clinical features and other biological parameters

\begin{tabular}{|c|c|c|c|c|c|c|c|}
\hline & patient & DMEI & Culture of the valve & $\begin{array}{l}\text { Blood cultures } \\
\text { during the cardiac } \\
\text { surgery ( } 3 \text { ) }\end{array}$ & $\begin{array}{l}\text { Blood cultures before the } \\
\text { cardiac surgery }\end{array}$ & $\begin{array}{l}\text { ATB before the } \\
\text { surgery (time) }\end{array}$ & $\begin{array}{l}\text { Intra-cellular } \\
\text { bacteria } \\
\text { serology }\end{array}$ \\
\hline \multirow[t]{19}{*}{ DPE+ } & 1 & Neg & S. epidermidis & 4 S. epidermidis & 1 & No & ND \\
\hline & 2 & ++1 & $\mathrm{Neg}$ & $4 S$ aureus & S. aureus & Yes 4 weeks & ND \\
\hline & 3 & Neg & S. epidermidis & Neg & S. epidermidis & & \\
\hline & 4 & +++1 & $\mathrm{Neg}$ & 3 S. epidermidis & S. epidermidis & Yes 4 weeks & ND \\
\hline & 5 & +++1 & $\mathrm{Neg}$ & & Streptococcus $s p^{2}$ & Yes & ND \\
\hline & 6 & $\mathrm{Neg}$ & $\mathrm{Neg}$ & $\mathrm{Neg}$ & 1 & Yes & $\mathrm{Neg}$ \\
\hline & 7 & $\mathrm{Neg}$ & $\mathrm{Neg}$ & Neg & Streptococcus $s p^{2}$ & Yes I month & ND \\
\hline & 8 & +++1 & Neg & ND & $\mathrm{Neg}$ & Yes 2 days & ND \\
\hline & 9 & +1 & $\mathrm{Neg}$ & 3 S. agalactiae & & & \\
\hline & 10 & Neg & $\mathrm{Neg}$ & & & & \\
\hline & 11 & Neg & $\mathrm{Neg}$ & $\mathrm{Neg}$ & S. pneumoniae & Yes I month & ND \\
\hline & 16 & $\mathrm{Neg}$ & $\mathrm{Neg}$ & $\mathrm{Neg}$ & & & \\
\hline & 17 & $\mathrm{Neg}$ & $\mathrm{Neg}$ & $\mathrm{Neg}$ & S. bovis & Yes > I month & ND \\
\hline & 18 & $\mathrm{Neg}$ & $\mathrm{Neg}$ & ND & ND & No & ND \\
\hline & 19 & $\mathrm{Neg}$ & P. acnes & ND & H. influenzae & Yes & Neg \\
\hline & 20 & Neg & $\begin{array}{l}\text { P. aeruginosa }+S . \\
\text { hominis }\end{array}$ & ND & Streptococcus $s p^{2}$ & Yes 2 months & ND \\
\hline & 24 & Neg & $\mathrm{Neg}$ & $\mathrm{Neg}$ & S. bovis & Yes 2 months & ND \\
\hline & & & & $\mathrm{Neg}$ & & & \\
\hline & & & & $\mathrm{Neg}$ & & & \\
\hline \multirow[t]{7}{*}{ DPE- } & 12 & $\mathrm{Neg}$ & Neg & ND & Campylobacter sp & Yes & ND \\
\hline & 13 & $\mathrm{Neg}$ & $\mathrm{Neg}$ & Neg & S. agalactiae & Yes I month & ND \\
\hline & 14 & $\mathrm{Neg}$ & $\mathrm{Neg}$ & $\mathrm{Neg}$ & Enterococcus sp & Yes I month & ND \\
\hline & 15 & $\mathrm{Neg}$ & S. epidermidis & $\mathrm{Neg}$ & 1 & No & ND \\
\hline & 21 & $\mathrm{Neg}$ & Neg & Neg & Staphylococcus sp & Yes & ND \\
\hline & 22 & Neg & $\mathrm{Neg}$ & Neg & S. pneumoniae & Yes I month & ND \\
\hline & 23 & $\mathrm{Neg}$ & $\mathrm{Neg}$ & ND & E. faecium & Yes 5 days & ND \\
\hline
\end{tabular}

DPE = direct pathological examination; DMEI = direct microscopic examination of imprints; I legend in bacteriological processing section, in all cases corresponding to Gram positif cocci; 2 Streptococcus sp was identified as belonging to streptococci viridans group; 3 the number before the species means the number of positive blood cultures; the ATB = antibiotic; Neg = negative; ND = not done; retrospective study impossible for patients $3,9,10,16$.

tures. The intracellular bacteria serologies (Bartonella, Coxiella, Chlamydiae, Legionella) were only performed in 3 patients (patients $6,19,26$ ) and were all negative. Patients 2 and 4, with a positive DMEI, were negative for valve culture. The antimicrobial therapy prescribed 4 weeks before surgery corresponding to the last positive blood culture, had probably sterilized the lesions. Valve culture was positive in 13 patients. 12 were evaluable and corresponded to 4 acute inflammatory processes and 8 chronic/sequellar processes. For the 8 true negative patients, except for patients 28 and 29 where bacterial blood cultures were known before surgery, the bacteria found in the valve could probably have been a contamination since the patients did not present evolutive clinical symptoms of endocarditis. As shown by Giladi et al.[6], valve culture is not recommended when acute endocarditis is not suspected. In the 4 endocarditis patients, 2 (patients 1 and 15 ) with no antimicrobial treatment had positive valve culture corresponding to the etiologic agent (Staphylococcus epidermidis). As described since 1990, the coagulase-negative staphylococci have been more and more implicated in native endocarditis [7]. The 2 other valve cultures were difficult to evaluate. Patient 20 was known to have had a blood culture documented on with a classical etiologic agent (Streptococcus viridans) and the mixed valve culture was probably a contamination. In another patient (patient 19) had a positive DMEI (Gram positive rod), a positive valve culture with Propionibacterium acnes, but a blood culture yielding Haemophilus influenzae. The microbiologist could not conclude anything from these results. P. acnes may often be considered as a contaminant, but in a few cases [8] this bacterium has been responsible for true endocarditis on native valves. This weak threshold of the direct microscopic examination of imprints could be due to antimicrobial therapy prescribed before cardiac sur- 
Table 2: Chronic/sequellar processes: results of DMEI, DPE, culture of valve and clinical features and other biological parameters

\begin{tabular}{|c|c|c|c|c|c|c|c|}
\hline & patient & DMEI & Culture of the valve & $\begin{array}{l}\text { Blood cultures } \\
\text { during the cardiac } \\
\text { surgery }\end{array}$ & $\begin{array}{l}\text { Blood cultures before the } \\
\text { cardiac surgery }\end{array}$ & $\begin{array}{l}\text { ATB before the surgery } \\
\text { (time) }\end{array}$ & $\begin{array}{l}\text { Intra-cellular } \\
\text { bacteria } \\
\text { serology }\end{array}$ \\
\hline \multirow[t]{3}{*}{ DPE+ } & 25 & Neg & S. hominis & Neg & l & Yes & ND \\
\hline & 26 & $\mathrm{Neg}$ & Neg & $\mathrm{Neg}$ & S. capitis Acinetobacter sp & Yes & Neg \\
\hline & 27 & $\mathrm{Neg}$ & Neg & ND & & & \\
\hline \multirow[t]{26}{*}{ DPE- } & 28 & $\mathrm{Neg}$ & P. acnes & ND & S. agalactiae & Yes $>15$ days & ND \\
\hline & 29 & $\mathrm{Neg}$ & P. acnes & ND & Streptococcus $s p^{2}$ & Yes 15 days & ND \\
\hline & 30 & $\mathrm{Neg}$ & Neg & ND & I & Yes 2 months & ND \\
\hline & 31 & Neg & Neg & Neg & l & No & ND \\
\hline & 32 & $\mathrm{Neg}$ & $\mathrm{Neg}$ & Neg & S. aureus & Yes 2 months & ND \\
\hline & 33 & Neg & Neg & Neg & S. aureus & Yes 3 days & ND \\
\hline & 34 & $\mathrm{Neg}$ & $\mathrm{Neg}$ & ND & I & Yes I month & ND \\
\hline & 35 & $\mathrm{Neg}$ & Neg & $\mathrm{Neg}$ & ND & Yes & ND \\
\hline & 36 & Neg & Neg & ND & & & \\
\hline & 37 & $\mathrm{Neg}$ & $\mathrm{Neg}$ & ND & S. aureus & Yes I month & ND \\
\hline & 38 & $\mathrm{Neg}$ & Neg & ND & ND & No & ND \\
\hline & 39 & $\mathrm{Neg}$ & P. acnes & ND & Neg & Yes 10 days & ND \\
\hline & 40 & $\mathrm{Neg}$ & S. epidermidis & ND & 1 & Yes 2 months & ND \\
\hline & 41 & $\mathrm{Neg}$ & Neg & ND & Streptococcus $s p^{2}$ & Yes & ND \\
\hline & 42 & $\mathrm{Neg}$ & $\mathrm{Neg}$ & ND & I & Yes 2 months & ND \\
\hline & 43 & $\mathrm{Neg}$ & $\mathrm{Neg}$ & Neg & I & Yes & ND \\
\hline & 44 & $\mathrm{Neg}$ & OPF & $\mathrm{Neg}$ & Neg & No & ND \\
\hline & 45 & $\mathrm{Neg}$ & $\mathrm{Neg}$ & $\mathrm{Neg}$ & 1 & Yes & ND \\
\hline & 46 & $\mathrm{Neg}$ & Neg & ND & I & No & ND \\
\hline & 47 & $\mathrm{Neg}$ & $\mathrm{Neg}$ & ND & ND & Yes II days & ND \\
\hline & 48 & $\mathrm{Neg}$ & Neg & ND & ND & No & ND \\
\hline & 49 & $\mathrm{Neg}$ & P. acnes & $\mathrm{Neg}$ & Neg & Yes 5 days & ND \\
\hline & 50 & $\mathrm{Neg}$ & Neg & ND & & & \\
\hline & 51 & $\mathrm{Neg}$ & Neg & ND & & & \\
\hline & 52 & $\mathrm{Neg}$ & Corynebacterium sp & ND & ND & No & ND \\
\hline & 53 & $\mathrm{Neg}$ & Neg & Neg & S. pneumoniae & Yes $>$ I month & ND \\
\hline
\end{tabular}

DPE = direct pathological examination, DMEI $=$ direct microscopic examination of imprints, 2 Streptococcus sp was identified as belonging to streptococci viridans group ATB = antibiotic; Neg = negative, ND = not done, OPF = oro-pharyngeal flora, retrospective study impossible for patients $27,36,50,51$.

Table 3: Performance of the DMEI, DPE and culture of cardiac native valves

\begin{tabular}{llllll}
\hline & sensitivity & specificity & PPV & NPV & \\
\hline & & & & $100 \%$ & $60 \%$ \\
DMEI & $21 \%$ & $90 \%$ & $84 \%$ & $76 \%$ & $51 \%$ \\
DPE & $66 \%$ & $69 \%$ & $36 \%$ & \\
culture & $21 \%$ & & \\
\hline
\end{tabular}

DMEI = direct microscopic examination of imprints, DPE = direct pathological examination, $P P V=$ positive predictive value, NPV $=$ negative predictive value 
gery and the fact that the patients came from a tertiary hospital receiving patients with a prolonged history of endocarditis.

\section{Conclusion}

Although DMEI is a major criterium of the von Reyn classification and is often rapidly available, it was found to be poorly informative in the assessment of endocarditis in this study. The presence of acute inflammation is the crucial point to evaluate the status of the endocarditis process. If in an acute context, no etiologic agent is known, such as fastidious bacteria [9], it is important to perform valve culture. The drawback of this technique is prior antibiotic therapy giving a poor yield. If the valve has undergone a chronic/sequellar process, the culture will not be informative. In this situation or in acute endocarditis, in a patient with no bacterial documentation and/or receiving antimicrobial treatment, it might be interesting to introduce routine molecular techniques [10]. Clinical context and histopathology are essential to validate the results of valve culture [11].

\section{References}

I. Chuard C, Antley CM, Reller LB: Clinical utility of cardiac valve stain and culture in patients undergoing native valve replacement. Arch Pathol Lab Med 1998, I 22:4I 2-4I5

2. Mainardi JL, Vandenesch F, Casalta JP, N'Guyen J, Benoît C, TissotDupont H, Maugein J, Weber M, Bouvet A, Etienne J, et al: Recommandations pour le diagnostic microbiologique et l'étude anatomopathologique des valves cardiaques au cours des endocardites infectieuses. Bull Soc Fr Microbiol 1995, 10:12-15

3. Gutschik E, the Endocarditis Working Group of the International Society for Chemotherapy: Microbiological recommendations for the diagnosis and follow-up of infective endocarditis. Clin Microbiol Infect 1998, 4:3S10-S16

4. Loire R, Vissuzaine C, Bruneval P: Recommandations pour le diagnostic des endocardites. Etude anatomopathologique des valves cardiaques. Ann Pathol 1995, 15:221-223

5. Durack DT, Lukes AS, Bright DK, Duke endocarditis service: new criteria for diagnosis of infective endocarditis: utilization of specific echocardiographic findings. Am J Med 1994, 96:200-209

6. Giladi M, Szold O, Elami A, Bruckner D, Johnson BL: Microbiological cultures of heart valves and valve tags are not valuable for patients without infective endocarditis who are undergoing valve replacement. Clin Infect Dis 1997, 24:884-888

7. Etienne J, Eyken SJ: Increase in native valve endocarditis caused by coagulase-negative staphylococci: an Anglo-French clinical and microbiological study. Br Heart J 1990, 64:38I-384

8. Günthard H, Hany A, Turina M, Wüst J: Propionibacterium acnes as a cause of aggressive aortic valve endocarditis and importance of tissue grinding: case report and review. J Clin Microbiol 1994, 32:3043-3045

9. Brouqui P, Raoult D: Endocarditis due to rare and fastidious bacteria. Clin Microbiol Rev 200 I, I 4:177-207

10. Goldenberger D, Künzli A, Vogt P, Zbinden R, Altweg M: Molecular diagnosis of bacterial endocarditis by broad-range PCR amplification and direct sequencing. J Clin Microbiol 1997, 35:27332739

II. Peterson LR, Hamilton JD, Baron EJ, Tompkins LS, Miller JM, Wilfert CM, Tenover FC, Thomson RB Jr: Role of clinical microbiology laboratories in the management and control of infectious diseases and delivery of health care. Clin Infect Dis 200I, 32:605611
Publish with BioMed Central and every scientist can read your work free of charge

"BioMedcentral will be the most significant development for disseminating the results of biomedical research in our lifetime." Paul Nurse, Director-General, Imperial Cancer Research Fund

Publish with BMC and your research papers will be:

- available free of charge to the entire biomedical community

- peer reviewed and published immediately upon acceptance

- cited in PubMed and archived on PubMed Central

- yours - you keep the copyright

Submit your manuscript here:

http://www.biomedcentral.com/manuscript/
BioMedcentral.com editorial@biomedcentral.com 